DOI: $10.18027 / 2224-5057-2017-7-3 s 1-47-51$

Цитирование: Кондакова И. В., Шашова Е. Е., Спирина Л. В., Колегова Е. С., Юнусова Н. В. Внутриклеточные протеолитические системы: новый класс маркеров для ранней диагностики и прогноза течения

злокачественных опухолей // Злокачественные опухоли. - 2017. - Т. 7. - № 3, спецвыпуск 1. - С. 47-51.

\title{
Внутриклеточные протеолитические системы: новый класс маркеров для ранней диагностики и прогноза течения злокачественных опухолей
}

\author{
И. В. Кондакова, Е. Е. Шашова, Л. В. Спирина, Е.С. Колегова, Н. В. Юнусова \\ Томский Национальный Исследовательский Медицинский Центр Российской академии наук, НиИ онкологии
}

\begin{abstract}
Резюме: известно, что злокачественный френотип опухоли фрормируется в результате изменения содержания патогенетически значимых белков в клетках, на которое оказывают влияние процессы протеиновой деградации. Поэтому изучение протеолиза и выявление компонентов протеолитических систем, ассоциированных с онкологическим процессом, перспективно для поиска маркеров злокачественной трансформации и опухолевой прогрессии. В обзоре проанализированы новые возможности определения активности и содержания компонентов внутриклеточных протеолитических систем - протеасом и кальпаинов для формирования групп онкологического риска среди больных гиперплазией эндометрия, прогноза метастазирования при плоскоклеточном раке головы и шеи, раке почки, раке яичников, а также предсказания эсрфективности противоопухолевой терапии. Использование этих новых маркеров в онкологической практике может расширить возможности для персонализированного подхода к лечению больных.
\end{abstract}

Ключевые слова: риск развития злокачественных опухолей, прогноз метастазирования, предсказание эффективности противоопухолевой терапии, протеасомы, кальпаины

\section{Информация об авторах:}

Ирина В. Кондакова, д. м. н., профессор, заведующий лабораторией биохимии опухолей НИИ онкологии Томского НИМЦ, г. Томск, Россия, e-mail: kondakova@oncology.tomsk.ru

Елена Е. Шашова, к. м. н., старший научный сотрудник лаборатории биохимии опухолей НИИ онкологии Томского НИМЦ, г. Томск, Россия, e-mail: schaschovaee@oncology.tomsk.ru

Людмила В. Спирина, д. м. н., старший научный сотрудник лаборатории биохимии опухолей НИИ онкологии Томского НИМЦ, г. Томск, Россия, e-mail: spirinalv@oncology.tomsk.ru

Елена С. Колегова, младший научный сотрудник лаборатории биохимии опухолей НИИ онкологии Томского НИМЦ, г. Томск, Россия, e-mail: elenakolegova@oncology.tomsk.ru

Наталья В. Юнусова, д. м. н., ведущий научный сотрудник лаборатории биохимии опухолей НИИ онкологии Томского НИМЦ, г. Томск, Россия, e-mail: bochkarevanv@oncology.tomsk.ru

В настоящее время актуальной проблемой онкологии является поиск маркеров метастазирования злокачественных новообразований различными высокотехнологичными методами, и зачастую кандидатными маркерами выступают показатели внутри- и внеклеточного протеолиза $[1,2]$. Важность проблемы поиска новых молекулярных маркеров также заключается в том, что эти показатели должны обладать высокой специфичностью, чувствительностью, подходить для использования при ус- ловии выраженной нозологической, морфологической и внутриклеточной гетерогенности злокачественных новообразований.

На биологические характеристики опухоли может повлиять постоянное изменение протеома, которое происходит под влиянием различных факторов в ходе трансформации нормальных клеток в опухолевые и при распространении онкологического процесса, что отражается в изменении регуляции рецепторов, компонентов сигнальных путей, 
факторов транскрипции, участвующих в формировании рака [3]. Одним из основных путей регуляции состава и качества протеома является протеолиз, опосредуемый убиквитин-протеасомной системой [4]. Протеасомная система является внутриклеточным мультикаталитическим мультисубъединичным комплексом, обладает тремя основными протеолитическими активностями: химотрипсинподобной (ХПА), трипсинподобной и каспазаподобной (КПА). В клетке они осуществляют протеолиз цитозольных, ядерных белков, превращение неактивных белков-предшественников в активные, участвуют в образовании регуляторных пептидов [5]. Каталитические комплексы протеасомной системы представлены двумя пулами: 20S- и 26S-протеасомы. Непосредственно протеолиз происходит в каталитическом комплексе, ядре - 20S протеасоме [6, 7]. В отсутствии регуляторной субъединицы при физиологических условиях вход в протеасому закрыт. Связывание регуляторной частицы (11S, 19S, РА200) с $\alpha$-кольцами контролирует состояние ворот и способствует многократному увеличению протеасомной активности [8]. Благодаря присоединению альтернативных регуляторов либо замене конститутивных субъединиц на иммунные может произойти формирование модифицированных форм протеасом, и это будет сопровождаться изменением протеасомальной активности [9]. Известно, что каталитические иммуносубъединицы (LMP-2 и LMP-7), благодаря усиленной экспрессии, встраиваются во вновь собирающиеся частицы протеасомы вместо конститутивных субъединиц, формируя иммунопротеасомы [10].

Протеасомы играют важную роль в патогенезе злокачественных опухолей. Продвижение клетки по клеточному циклу регулируется специфическими белками - циклинами путем последовательной активации циклинзависимых киназ (CDK). Циклины являются достаточно нестабильными и существуют в клетке непродолжительное время. Их наличие и количество в клетке контролируется, с одной стороны, факторами транскрипции и, с другой стороны, протеасом-зависимой деградацией. Убиквитин-протеасомная система принимает участие как в разрушении самих циклинов, их комплексов, так и в регуляции стабильности CDK-ингибиторов [11]. Убиквитин-протеасомная система может играть важную роль не только в стимуляции пролиферации, но и в приобретении трансформированными клетками невосприимчивости к антиростовым сигналам, деградируя наравне с каспазами белок гена ретинобластомы $\mathrm{pRb}$ (retinoblastoma protein) при участии убиквитин-лигазы Mdm2 (mouse double minute 2) и разрушая многие компоненты сигнального пути, опосредованного TGF- $\beta$, важного рост-ингибирующего цитокина [12]. Кроме того, убиквитин-протеасомная система вовлечена в регуляцию апоптоза. Многие ядерные белки, опосредующие программируемую клеточную гибель, являются субстратами для протеасом: транскрипционные факторы (c-Fos, c-Myc, AP-1), опухолевый супрессор р53, ингибитор NF-
kB IkB, белки, контролирующие клеточный цикл, белки семейства Bcl-2, белки, контролирующие активность каспаз (IAPs) и участвующие в проведении проаптотического сигнала (cFLIP) [13]. Описано участие протеасом в регуляции доступности эстрогеновых рецепторов, и, кроме того, в разрушении рецепторов прогестерона, в снижении экспрессии рецепторов EGFR и HER-2/neu, участие в деградации рецепторов инсулиноподобных факторов роста гормонов [14-16]. Наши данные показывают, что в опухолевой ткани молочной железы активность и состав протеасом варьирует в зависимости от наличия или отсутствия в них рецепторов эстрогенов и прогестерона [17].

Другим важным молекулярным механизмом развития и прогрессирования рака является внутриклеточный протеолиз, опосредованный кальпаиновой системой. Кальпаины представляют собой кальций-зависимые цитозольные цистеиновые протеиназы (КФ 3.4.22.17); в настоящее время известно, что в состав кальпаиновой системы входят 15 протеаз [18]. Кальпаиновая система деградации белков также осуществляет разрушение большого количества внутриклеточных белков, в том числе различных сигнальных белков, белков-онкогенов и онкосупрессоров [19]. Кальпаины вовлечены в регуляцию апоптоза, пролиферации и подвижности клеток, на которую они влияют путем участия в реорганизации актинового цитоскелета [20, 21]. Существуют данные, показывающие участие кальпаинов в образовании опухолей молочной железы и глиом $[22,23]$.

В связи с важной ролью внутриклеточного протеолиза в патогенезе злокачественного роста в нашей работе была исследована связь содержания и активности компонентов внутриклеточного протеолиза с переходом облигатного предрака - атипичной гиперплазии эндометрия в рак. Показано, что общая активность кальпаинов в ткани рака эндометрия была в шесть раз выше по сравнению с гиперплазией [24]. Однофакторный логистический регрессионный анализ показал, что активность кальпаинов в гиперпластически измененной ткани эндометрия может быть независимым предиктором развития рака. На основе этих данных был разработан способ оценки риска развития рака эндометрия у больных с гиперпластическими процессами эндометрия [25].

Усиление протеолиза в опухолевых клетках обусловлено высоким уровнем метаболизма и интенсивностью таких процессов, как пролиферативная активность, инвазивный рост, метастазирование [26]. В клетках неоплазмы происходит постоянное обновление белкового и пептидного состава. К числу белков, экспрессия которых важна для инвазивного роста и метастазирования, относятся локомоторные белки, участвующие в ремоделировании актинового цитоскелета [27-29]. Показано, что протеасомная система играет важную роль на этапах метастазирования. Увеличение ХПА активности протеасом характерно для рака щитовидной железы, рака толстой кишки при распространении опухоли на регионарные лимфоузлы 
[30, 31]. В то же время при раке молочной железы при обширном лимфогенном метастазировании наблюдается значительное угнетение активности протеасом [32]. Вероятно, снижение активности протеасом может быть вызвано нарушением процессов посттрансляционной модификации (например, фосфорилированием) субъединиц протеасом. В частности, в некоторых экспериментальных работах продемонстрировано, что блокирование фосфорилирования Rpt3-T25 ингибирует 26S протеасомную активность примерно на 30\%. При этом снижаются все 3 типа активности данных протеолитических ферментов [33].

Актуальность возможности использования показателей протеолитических систем для оценки прогноза продиктована доказательством их роли на этапах прогрессии при злокачественных новообразованиях различной локализации. Используемые в настоящее время прогностические и предсказательные критерии далеко не всегда позволяют оценить риск прогрессирования заболевания у больных с высокой степенью надежности и, следовательно, определить индивидуальный план лечения. Поэтому проблема персонифицированного подхода к лечению онкологических больных имеет большое научное и практическое значение. Поиск молекулярных маркеров прогноза течения заболевания приобретает большое значение [34, 35].

Показана связь протеасомной системы с гематогенным, лимфогенным метастазированием рака и выживаемостью онкологических больных. Так, при плоскоклеточном раке головы и шеи высокая ХПА протеасом в опухолевой ткани связана с хорошим прогнозом 2-летней общей выживаемости больных [36]. При светлоклеточном раке почки, характеризующимся появлением отдаленных метастазов, наблюдалось выраженное снижение тотальной активности протеосом по сравнению с опухолями без метастазов [37]. Показано, что при эпителиальном раке яичников концентрация циркулирующих в плазме крови протесом до лечения была выше, чем у здоровых доноров, а после завершения первичного лечения выше, чем до лечения, и ассоциировалась с объемом остаточной опухоли и общей выживаемостью [38]. Также у больных раком яичников низкая активность протеасом и кальпаинов в ткани пер- вичной опухоли ассоциировалась с интраперитонеальным метастазированием [39]. Кроме того, высокая экспрессия кальпаина 2 в ткани рака яичников ассоциировалась с хорошей безрецидивной и общей выживаемостью больных [40]. При проведении анализа выживаемости у больных раком ободочной кишки установлено, что высокий уровень ХПА протеасом и общей кальпаиновой активности в опухоли ободочной кишки являются неблагоприятными факторами в отношении 2-летней безметастатической выживаемости [41]. Повышенная экспрессия мРНК кальпаина 4 является независимым предиктором плохого прогноза у пациентов раком желудка после гастрэктомии [42].

Кроме того, содержание и активность протеасом в тканях, по-видимому, могут отражать чувствительность опухолей к традиционным цитостатическим и таргетным препаратам. Так, при раке почки отмечается изменение активности кальпаинов и протеасом после проводимого лечения эверолимусом и ингибиторами тирозинкиназ $[43,44]$. Активность внутриклеточных протеиназ у больных диссеминированным раком почки имела ряд особенностей. На фоне приема таргетных препаратов выявлено снижение активности протеасом в 3,33 раза у больных с хорошим прогнозом, при этом активность кальпаинов оставалась неизменной. Динамика изменений активности внутриклеточных протеиназ у больных с промежуточным прогнозом была противоположной: в ткани опухоли активность протеасом на фоне лечения не изменялась, а активность кальпаинов увеличилась в 8,6 раза [44]. Возможно, в связи с этим можно обсуждать роль кальпаинов в механизмах прогрессирования заболевания у больных с промежуточным прогнозом и рассматривать этот показатель в качестве прогностического.

Таким образом, значение и биологическая роль протеасом и кальпаинов в развитии злокачественных опухолей важна как на этапах канцерогенеза, так и последующей опухолевой прогрессии. На сегодняшний день результаты о возможности определения протеасом как маркеров прогноза метастазирования и эффективности проводимого лечения представляются весьма перспективными и требуют дальнейшего изучения.

\section{Литература • References}

1. Кондакова И. В., Клишо Е. В., Савенкова О. В., Какурина Г. В., Чойнзонов Е. Л., Шишкин Д. А., и др. Матриксные металлопротеиназы 2 и 9 и их тканевые ингибиторы как факторы метастазирования злокачественных новообразований головы и шеи // Биомедицинская химия. - 2008. - Т. 54. - №5. - С. 555-560.

2. Спирина Л. В., Кондакова И. В., Клишо Е. В., Какурина Г. В., Шишкин Д. А. Металлопротеиназы как регуляторы неоангиогенеза в злокачественных новообразованиях // Сибирский онкологический журнал. - 2007. - № 1. - c. 67-71. http://www.oncology. tomsk.ru/nii/gournal/2007/1/information/soj_\%202007_1_67-71.pdf.

3. Моисеенко Ф.В., Волков Н. М., Богданов А. А., и др. Современные возможности клинического применения экспрессионного типирования опухолей молочной железы // Вопросы онкологии. - 2016. - Т62. - №2 2. - с. 31-34.

4. Колегова Е. С., Кондакова И. В., Завьялов А. А. Малые белки теплового шока и убиквитин-протеасомная система при злокачественных опухолях // Вопросы онкологии. - 2016. - №3. - с. 401-405. 
5. Lub S., Maes K., Menu E., et al. Novel strategies to target the ubiquitin proteasome system in multiple myeloma. // Oncotarget. 2016. - 7 (6). - p. 6521-6537. - doi: 10.18632/oncotarget. 6658.

6. Сорокин А. В., Ким Е.Р., Овчинников Л. П. Протеасомная система деградации и процессинга белков // Успехи биологической химиии - 2009. - Т. 49. С. 3-76. http://www.inbi.ras.ru/ubkh/49/Sorokin.pdf.

7. Шарова Н. П., Астахова Т. М., Карпова Я. Д. и др. Множественные фрормы протеасом как мишени противоопухолевых лекарств нового поколения. // Онкохирургия. - 2011. - Т. 3. - №2. - с. 37-42.

8. Jung T., Grune T. The proteasome and the degradation of oxidized proteins: Part I - structure of proteasomes // Redox Biol. - 2013. 1 (1).-p. 178-182. doi: 10.1016/j. redox. 2013.01.004.

9. Mani A., Gelmann E. P. The ubiquitin-proteasome pathway and its role in cancer. // J. Clin. Oncol. - 2005. - Vol. 23. - P. 4776-4789.

10. Joyce S. Immunoproteasomes edit tumors, which then escapes immune recognition // Eur. J. Immunol. - 2015. - November. p. 1-5. - DOI: 10.1002/eji. 201546100.

11. Tu Y., Chen C., Pan J., et al. The ubiquitin proteasome pathway (UPP) in the regulation of cell cycle control and DNA damage repair and its implication in tumorigenesis // Int. J. Clin. Exp. Pathol. - 2012. - Vol. 5, No. 8. - P. 726-738. https:// www.ncbi.nlm.nih.gov/pmc/articles/PMC3466981/.

12. Glasgow E., Mishra L. Transforming growth factor-beta signaling and ubiquitinators in cancer // Endocrine-Related Cancer. - 2008. Vol. 15. - P. 59-72. doi: 10.1677/ERC-07-0168.

13. Цимоха А. С. Протеасомы: участие в клеточных процессах. // Цитология. - 2010. - Т. 52, №4. - С. $277-300$.

14. Ogawa S., Shih L.-Y., Suzuki T., Otsu M., Nakauchi H., et al. Deregulated intracellular signaling by mutated C-CBL in myeloid neoplasms. //Clinical Cancer Research. - 2010. - Vol. 16. - P. 3825-31.

15. Powers G. L., Ellison-Zelski S. J., Casa A. J., et al. Proteasome inhibition represses ER gene expression in ER+ cells - a new link between proteasome activity and estrogen signaling in breast cancer/ // Oncogene. - 2010. - Vol. 29. - P. 1509-1518.

16. Broussas M., Dupont J., Gonzalez A., Blaecke A., Fournier M, et al. Molecular mechanisms, involved in activity of h7C10, a humanized monoclonal antibody, to IGF-1 receptor // Int. J. Cancer. - 2009. - Vol. 124, № 10. - P. 2281-2293. doi: 10.1002/ijc. 24186.

17. Shashova, EE Lyupina, YV Glushchenko, SA Slonimskaya, EM Savenkova, et al. Proteasome Functioning in Breast Cancer: Connection with Clinical-Pathological Factors //PLoS ONE. - 2014. - 9 (10): e109933. https://doi.org/10.1371/journal. pone. 0109933.

18. Бондарева Л. А., Немова Н. Н., Кяйвяряйнен Е. И. Внутриклеточная Са-зависимая протеолитическая система животных. // М.: Наука. - 2006. - 294 c.

19. Bernaudo S, Khazai S, Honarparvar E, Kopteva A, Peng C. Epidermal growth factor promotes cyclin G2 degradation via calpainmediated proteolysis in gynaecological cancer cells.// PLoS One. - 2017. - 12 (6).-e0179906.

20. Bravo-Cordero JJ, Cordani M, Soriano SF, Diez B, Munoz-Agudo C, et al. A novel high-content analysis tool reveals Rab8-driven cytoskeletal reorganization through Rho GTPases, calpain and MT1-MMP. // J. Cell Sci. - 2016. - 129 (8).-p. 1734-1749. doi: 10.1242/jcs. 174920.

21. Ma D, Fang J, Liu Y, Song JJ, Wang YQ, et. al. High level of calpain1 promotes cancer cell invasion and migration in oral squamous cell carcinoma. // Oncol. Lett. - 2017. - 13 (6). - p. 4017-4026. doi: 10.3892/ol. 2017.5970.

22. Cai J. J., Qi Z.X., Hua W., Zhu J. J., Zhang X., et al. Increased expression of Capn4 is associated with the malignancy of human glioma. // CNS Neurosci Ther. - 2014. - 20 (6). -p. 521-527.

23. Grieve S, Gao Y, Hall C, Hu J, Greer PA. Calpain Genetic Disruption and HSP90 Inhibition Combine To Attenuate Mammary Tumorigenesis. // Mol Cell Biol. - 2016. - 36 (15).-p. 2078-2088. doi: 10.1128/MCB. 01062-15.

24. Коваль В.Д., Спирина Л. В., Кондакова И. В., Коломиец Л. А., Шпилева О. В. Активность протеасом и кальпаинов при новообразованиях эндометрия. // Молекулярная медицина. -2012. -№4. - С. 45-48.

25. Коваль В.Д., Кондакова И. В., Спирина Л.В., Коломиец Л. А., Чернышова А. Л. Способ оценки рака эндометрия у больных с гиперпластическими процессами эндометрия. // Патент на изобретение -2015 г. -RUS 2554505, 28.05.

26. Spirina L. V., Kondakova I. V., Choinzonov E. L., et al. Activity and subunit composition of proteasomes in head and cervical squamous cell carcinomas // Bulletin of Experimental Biology and Medicine. - 2010. -149 (1). - p. 82-85.

27. Бочкарева Н. В., Кондакова И. В., Коломиец Л. А. Роль актинсвязывающих белков в клеточном движении в норме и при опухолевом росте // Молекулярная медицина. - 2011. - №6. - С. 14-18.

28. Kondakova I.V., Yunusova N. V., Spirina L. V., et al. Association between intracellular proteinase activities and the content of locomotor proteins in tissues of primary tumors and metastases of ovarian cancer // Russian Journal of Bioorganic Chemistry. - 2014. - 40 (6). - p. $681-687$.

29. Liu F, Zhou J, Zhou P, et al. The ubiquitin ligase CHIP inactivates NF- $\kappa B$ signaling and impairs the ability of migration and invasion in gastric cancer cells. // Int J Oncol. - 2015. -vol. 46 (5). - P. 2096-2106. doi: 10.3892/ijo. 2015.2893. 
30. Shashova E. E., Astakhova T. M., Plekhanova A. S., et al. Changes in proteasome chymotrypsin-like activity during the development of human mammary and thyroid carcinomas // Bulletin of Experimental Biology and Medicine. - 2013. - 156 (2). - p. $242-244$.

31. Ivanova E. V., Kondakova I. V., Spirina L. V., et al. Chymotrypsin-like activity of proteasomes and total calpain activity in gastric and colorectal cancer. // Bulleten of Experimental Biology and Medicine. - 2014. - 157 (6). - p. 781-784.

32. Шашова Е. Е., Кондакова И. В., Слонимская Е. М., Глущенко С. А., Колегова Е. С. Изменение химотрипсинподобной и каспазоподобной активностей протеасом в зависимости от степени распространенности рака молочной железы // Сибирский онкологический журнал. - 2013. - №5 (59). - С. 45-49.

33. Guo X., Wang X., Wang Z. et al. Site-specific proteasome phosphorylation controls cell proliferation and tumorigenesis. // Nat Cell Biol. - 2016. - 18 (2).-p. 202-212. doi:10.1038/ncb3289.

34. Какурина Г.В., Кондакова И. В., Чойнзонов Е. Л. Прогнозирование метастазирования плоскоклеточных карцином головы и шеи // Вопросы онкологии. 2012. Т. 58. №1. С. 26-32.

35. Какурина Г.В., Кондакова И. В., Чойнзонов Е. Л. Постгеномные технологии в прогнозе метастазирования плоскоклеточных карцином головы и шеи // Российский биотерапевтический журнал. - 2011. - Т. 10. - №3. -С. 31-36.

36. Чойнзонов Е. Л., Спирина Л.В., Кондакова И. В., Чижевская С. Ю., Шишкин Д.А., и др. Прогностическая значимость определения активности протеасом в тканях плоскоклеточных карцином головы и шеи // Сибирский научный медицинский журнал. - 2014. -Т. 34. - №4. -с. 103-108.

37. Спирина Л. В., Кондакова И. В., Усынин Е. А., Юрмазов З. А. Регуляция экспрессии транскрипционных факторов и фрактора роста эндотелия протеасомной системой при метастазировании рака почки // Вестник РОНЦ им. Н. Н. Блохина РАМН. 2012. - T. 23. -№1. - C. 27-32.

38. Heubner M., Wimberger P., Dahlmann B., Kasimir-Bauer S., Kimmig R., et al. The prognostic impact of circulating proteasome concentrations in patients with epithelial ovarian cancer // Gynecol. Oncol. - 2011. - Vol. 120 (2). - P. 233-238.

39. Юнусова Н. В., Спирина Л. В., Кондакова И. В., Коломиец Л. А., Виллерт А. Б., Шпилева О.В.Экспрессия и активность протеаз при метастазировании рака яичников // Известия Российской академии наук. Серия биологическая. 2014. № 5. С. $448-455$.

40. Storr S. J., Safuan S., Woolston C. M. et al. Calpain_2 expression is associated with response to platinum based chemotherapy, progression_free and overall survival in ovarian cancer // J. Cell. Mol. Med. - 2012. V. 16. - № 10. - P. 2422-2428.

41. Иванова Э. В., Черемисина О.В., Афанасьев С. Г., Кондакова И. В. Активность протеасом и кальпаинов при раке ободочной кишки: связь с метастазированием и прогнозом заболевания // Вопросы онкологии. -2016. - Т. 62. - №6. - c. 794-800. Peng P, Min L, Song S, Zhao J, Li L, et. al. Elevated expression of calpain-4 predicts poor prognosis in patients with gastric cancer after gastrectomy. // Int J Mol Sci. - 2016. - 17 (10). P. 1612.

42. Спирина Л.В., Усынин Е.А., Кондакова И. В., Юрмазов З.А., Слонимская Е. М. Влияние таргетной терапии на содержание транскрипционных, ростовых фракторов, протеинкиназы mTOR и активности внутриклеточных протеиназ у больных диссеменированным раком почки // Бюллетень экспериментальной биологии и медицины. 2015. Т. 160. № 12. С. $768-772$.

43. Юрмазов 3. А., Спирина Л. В., Усынин Е.А., Кондакова И. В., Слонимская Е. М. Молекулярные показатели, связанные с эффрективностью терапии эверолимусом у больных диссеменированным раком почки // Сибирский онкологический журнал. 2016. Т. 15. №2. C. 42-47. DOI: http://dx.doi.org/10.21294/1814-4861-2016-15-2-42-47. 